\title{
Mechanical behavior of ballasted railway track stabilized with polyurethane: A finite element analysis
}

\author{
Zelimkhan Khakiev, Alexander Kruglikov, Georgy Lazorenko ", Anton Kasprzhitskii, Yakov \\ Ermolov and Victor Yavna \\ Rostov State Transport University, Chair of Physics, Narodnogo Opolcheniya Sq., Rostov-on-Don, \\ 344038, Russian Federation
}

\begin{abstract}
Analysis of mechanical behavior of ballast shoulder of railway track reinforced by polyurethane binding agent has been performed by the method of finite-element simulation Limitation of the model of linearelastic properties of geocomposite has been displayed. Dependence of elasticity modulus of geocomposite on deformation value has been suggested. Influence of penetration depth of polyurethane binding agent on behavior of railway track construction under different train loads has been studied.
\end{abstract}

\section{Introduction}

In the conditions of organizing the traffic of heavy freight and passenger high-speed trains, the level of force impact on the railway track inevitably increases. The frequency of applying this load also increases, which makes special requirements on the design and maintenance of the track [1]. With a continuous increase in dynamic loads on the ballasted track, associated with the growth of speeds and axle loads from modern rolling stock, additional measures are required to improve the stability of the structure in the longitudinal and transverse directions.

A possible solution to the problem of increasing the lateral resistance to the movement of sleepers under the impact of the train load is to strengthen the ballast shoulders. This, increases lateral resistance to shear of the track structure in an unloaded static state (from $10 \%$ [2] to $30 \%$ [3]). Various technical solutions are used to provide the required indicators of stability and reliability of the railway track. These include the optimization of the friction properties of the permanent way by changes in its geometric dimensions, such as thickness and width along the top, as well as the shape of the ballast shoulder itself $[4,5]$. The type and shape of the ballast material has a noticeable effect on the lateral stability of the railway track. It was shown in [5] that steel slag ballast has an average of $27 \%$ more lateral resistance than a limestone material. Increasing the resistance of ballast to the transverse shear of a sleeper can be achieved by optimizing its shape. Tto solve this problem, the possibility of changing the base profile of a sleeper is considered in work $[6,7]$. The studies

* Corresponding author: glazorenko@yandex.ru 
carried out in $[8,9]$ have shown that using the geosynthetics from periodic structures has allowed to reduce the transverse deformations of the new ballast by approximately $49 \%$ and the purified one by $11 \%$.

Positive results in strengthening the structure of the railway track can be obtained by using polymeric materials. At present, they are used to improve the properties of the subballast layer and subgrade [10-12]. Besides, polymeric materials are also can be used for the organization of transition zones at the railway by matching the elastic dynamic characteristics of various structures [18, 19], creating nodes and parts of the upper track structure elements $[13,14]$. The use of polymeric materials to stabilize ballast allows to counteract the wear of ballast material and improve its strength properties [15]. One of the main advantages of this technology is the possibility of strengthening the ballast at any desired level and location, without impairing the drainage properties of the ballast [16]. The concept of ballast improvement by polymer systems based on polyurethane is discussed in [17]. Significant advances in ballast strengthening by polymers were achieved using polyurethane [18].

In the paper [19], the transverse shear forces arising from the sleeper and measured in $[4,5,20-22]$ are compared with similar measurements made after strengthening the ballast shoulder with polyurethane binders. It is found that the formation of the geocomposite from the strengthened by the polymer ballast leads to a significant increase in the contribution of the ballast shoulder to resistance to transverse shear due to the formation of the geocomposite beam. With shifts exceeding $20 \mathrm{~mm}$, the geocomposite beam begins to define the total resistance to lateral displacement of the sleepers. In addition, it is established that the resistance force to the transverse shear on the side of the geocomposite beam increases nonlinearly with a transverse sleeper shear. Thereby, the problem of investigating the mechanical behavior of the geocomposite arises in places of the greatest deformations. The statement of the research task of this work is related to the fact that the growth of the lateral displacement of sleepers can lead to the destruction of the beam when critical angles of bending are reached, determined by the mechanical properties of the deformed geocomposite. The solution of the problem in the paper was carried out by the finite element modeling of the behavior of the ballast shoulder reinforced with a polyurethane binder, experimentally studied in [19] and at the Transbaikal Railway (Russian Railways) test site with small-radius curves. Influence of penetration depth of binding agent on mechanical behavior of railway track construction under different train loads is being studied.

\section{Methods}

The computer simulation of mechanical behavior of the railway ballast shoulder containing the geocomposite was performed in Comsol Multiphysics software. The three-dimensional model of the ballast shoulder (Fig. 1) is created by the software GUI, including a shoulder reinforced with a polymeric binding material (position 1), a sloping part (position 2), and a subgrade represented by loose ballast material (position 3). As a prototype of the model, a section of the railway was used, strengthened with a polymeric binder. A general view of the computer model is shown in Figure 1.

Software Plaxis has been applied to study influence of penetration depth of binding agent on mechanical behavior of railway track construction under different train loads. This task has been carried out with the help of axisymmetric model (Fig. 2b), simulating standard construction of ballasted railway track on single-line section with geometric sizes pictured in Figure 2a. 

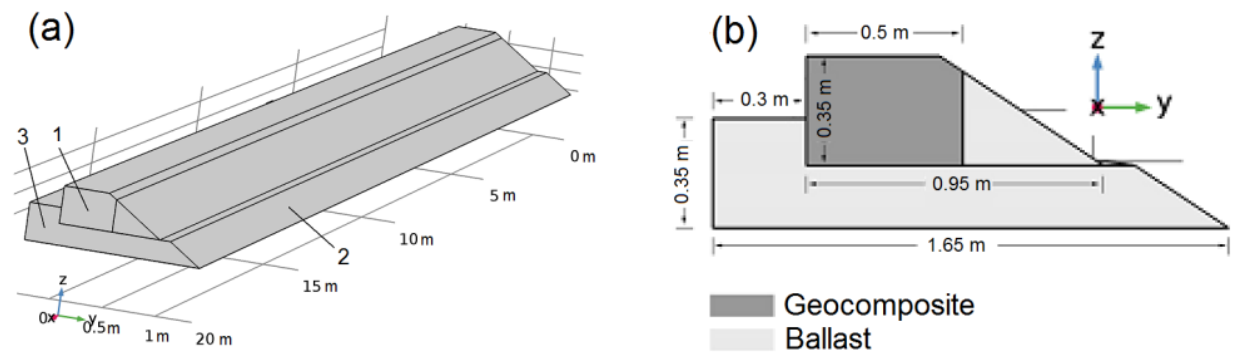

Fig. 1. 3d (a) and cross-sectional (b) views of the model of ballast shoulder stabilized with polyurethane.

(a)

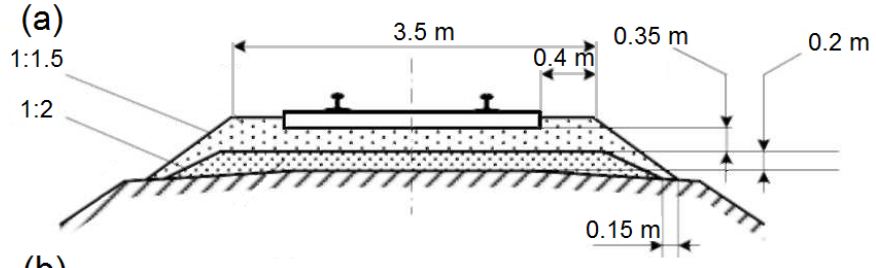

(b)

Axis of Symmetry

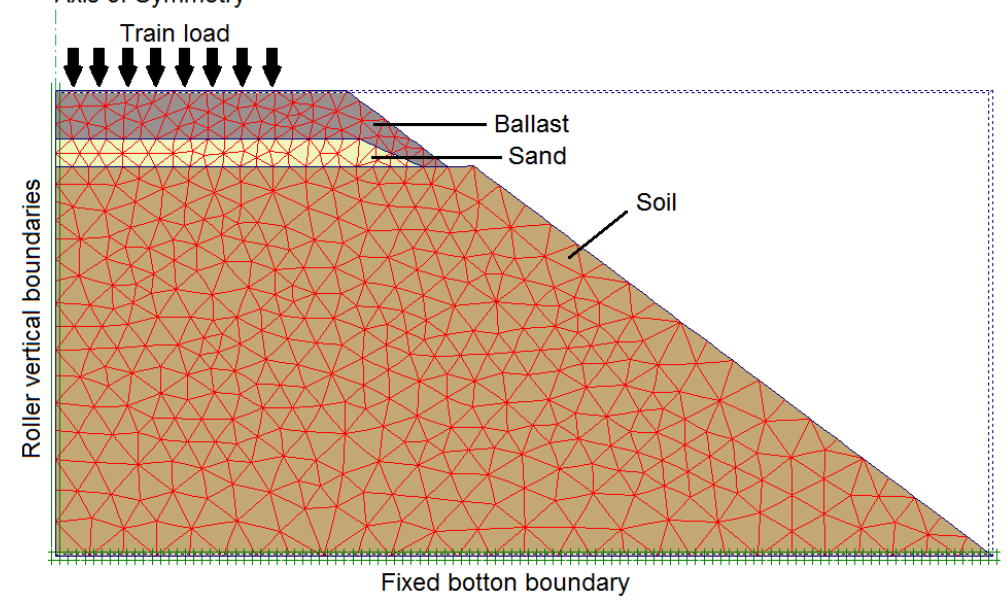

Fig. 2. Cross-sectional view (a) and finite element mesh (b) of the model of ballasted railway track.

The physico-mechanical properties of the computer model are defined: the density $(1850 \mathrm{~kg} / \mathrm{m} 3)$, the elasticity modulus $(70 \mathrm{MPa})$ and Poisson's ratio $(0.33)$ of the ballast material. To describe the properties of the geocomposite, the value of the elasticity modulus is assumed equal to $360 \mathrm{MPa}$. This value was obtained as a result of dynamic measurements on the test site using the densimeter PDU-MG4.01. Physical mechanic properties of materials for model in Figure 2 are adopted from the work [23]. As boundary conditions (Fig. 1), it is assumed that the ends of the geocomposite are in a static state. The linear-elastic material approximation is used, for which tensors of stresses and deformations are calculated in accordance with the generalized Hooke's law. The Coulomb static friction approximation is considered with a coefficient of friction equal to 0.9. The coefficient of friction between the geocomposite and the ballast is assumed to be the same with the coefficient of friction "ballast by ballast". The calculation was carried out by the finite element method. Border conditions of the model in Figure 2 include complete fixing in the ground bed of the model and sliding fixing in the vertical border. 


\section{Results and discussion}

\subsection{Influence of model parameters on the calculated value of the lateral displacement of the structure}

As a result of the calculations, the stress-strain state (SSS) of the system under load was obtained, and also the total displacement of the structure was determined.

The calculations of lateral displacement of sleepers with different length of track section and magnitude of Young's modulus of geocomposite have been performed at the first stage. Calculation results for the transverse force applied to the geocomposite, equal $20 \mathrm{kN}$ on the surface of the contact area which equates the area of the sleeper end $\left(0.0387 \mathrm{~m}^{2}\right)$, are given in Figure 3a. The given data enable to conclude that the length encrease of the model from $20 \mathrm{~m}$ to $24 \mathrm{~m}$ (up to $20 \%$ ) results in changes of transverse rail travel from $4,8 \mathrm{~mm}$ to 7,8 $\mathrm{mm}$ (up to $50 \%$ ). Alongside with this, the growth of Young's modulus from $360 \mathrm{MPa}$ (experimental value of unloaded geocomposite) to $460 \mathrm{MPa}$ (up to $25 \%$ ) decreases the transverse travel from $7.8 \mathrm{~mm}$ to $7.1 \mathrm{~mm}$ (up to $10 \%$ ) on the shoulder length of $24 \mathrm{~m}$.
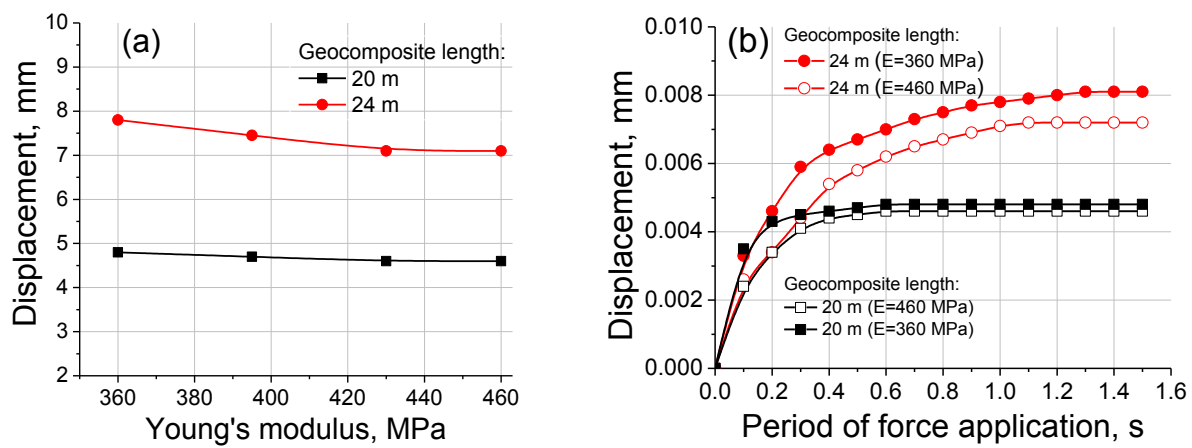

Fig. 3. Dependence of ballast shoulder displacement on Young's modulus under application of transverse forces equal $20 \mathrm{kN}$ (a); convergence of numerical procedures for the geocomposite with length $20 \mathrm{~m}$ and $24 \mathrm{~m}$ (b).

Dependences of transverse travel of the ballast prism shoulder on the time of application of transverse force are given in Figure $3 \mathrm{~b}$. The figure illustrates the quality and the speed of convergence of numerical procedures for different values of lengths and Young's modulus of geocomposite. It's obvious that the growth of these values results in the considerable increase of the required time of travel calculation. Thus, under the change of the geocomposite length from $20 \mathrm{~m}$ to $24 \mathrm{~m}$ the calculation time of the value of transverse travel increases $1.5-2.0$ times. That corresponds to the extra 18-24 hours of commercial time if the computer Super Micro, which has got 24 nuclei, is used.

The results of measuring the resistance force of the ballast prism shoulder containing geocomposite, appearing under transverse shift of metal plate which models a tie are given in Figure 4. The same figure displays the approximation of experimental values having exponential dependence of the following type:

$$
F=f_{0}+F_{0} e^{-x / \tau},
$$

where $\tau=5.31 \mathrm{~mm}, f_{0}=26.17 \mathrm{kN}, F_{0}=-24.87 \mathrm{kN}, x$ - lateral displacement.

The calculation results of transverse force obtained under constant value of Young's modulus equal to the experimental value for unloaded geocomposite $E=360 \mathrm{MPa}$ are 
given in Figure 4. It's obvious that the travels which don't exceed $6 \mathrm{~mm}$ the calculation values of the forces are less than the experimental ones.

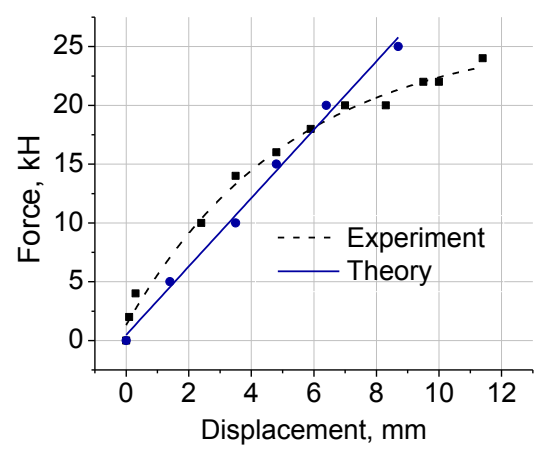

Fig. 4. The relation of lateral shear and the force applied if the shoulder length of the ballast prism is $23 \mathrm{~m}$.

The increase of travels (values over $6 \mathrm{~mm}$ ) results in the exceeding of the calculation values of forces over the experimental ones. Application of linear-elastic model under some other values of elasticity modulus will not enable to reproduce the curve approximating experimental data of exponential dependence. The change of elasticity modulus in the calculation model will result in changes of slope ratio of theoretical linear dependence that displays the functional dependence of value of transverse travel and appearing force. In order to improve the convergence of the obtained theoretical and experimental data one should take into account the dependence of elastic properties of geocomposite on deformations and strain and stress.

\subsection{Calculation of the lateral displacement of the ballast prism shoulder in the model of nonlinear elastic properties of geocomposite}

At the next stage of modeling, the dependence of the elastic modulus on the values of geocomposite deformations is taken into account, which is illustrated by Figure 5 .

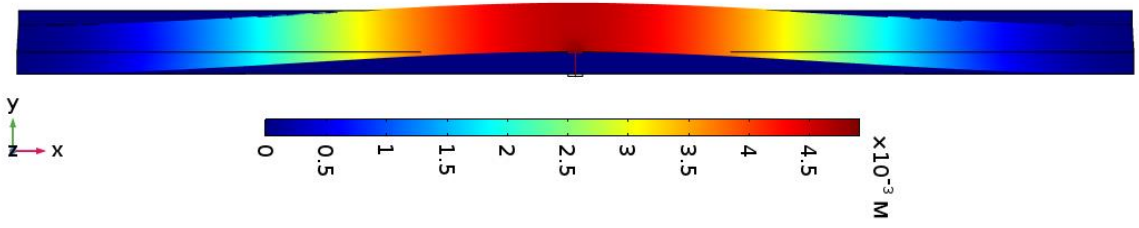

Fig. 5. Changes in the lateral deformation in a geocomposite $23 \mathrm{~m}$ long with a force of $20 \mathrm{kN}$.

It is obvious that for realization of this representation it is necessary to provide possibility to set dependence of the Young's modulus on a linear coordinate in the finite element model. To reach this goal, the geocomposite beam is divided into 7 sections with lengths of 1-3 and 5-7, equal to $3 \mathrm{~m}$ and a central section with a length of 5 meters. The values of the Young's modulus of the sections are given in Figure 6a, their values are used to calculate the displacement of the central point of the beam when applying the longitudinal force. It is assumed that the sections of the beam with numbers 1 and 7, 2 and 6,3 and 5 have the same modulus of elasticity. The results of calculations and their linear approximations are compared with the experiment in Figure 6b. Comparison of the results 
allows us to conclude that the experimental dependences of the sleeper displacement under the application of force can be explained by reducing the components of the Young's modulus of the geocomposite in the direction of the deforming force. The Young's modulus values used in the calculation (Fig. 6) selected not contradicting the formula (1) in the range of values up to $360 \mathrm{MPa}$ obtained for the unloaded geocomposite.
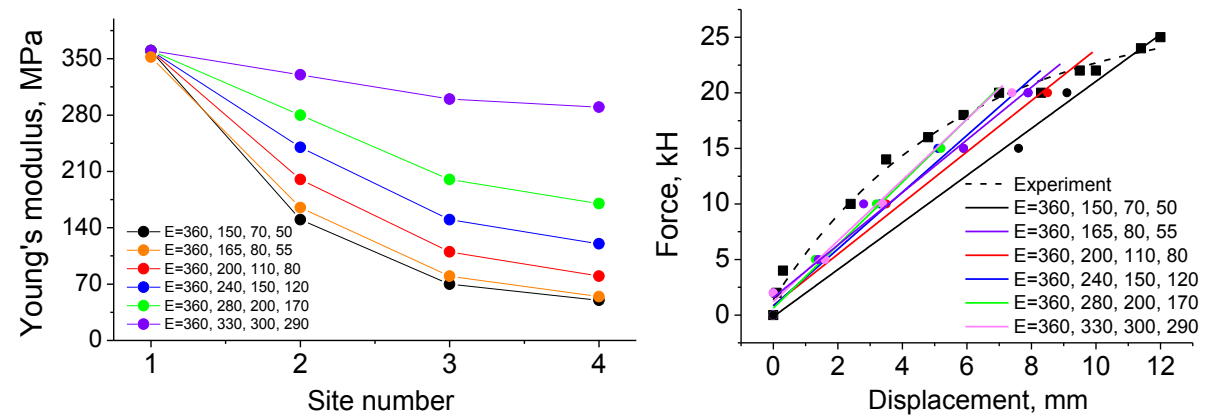

Fig. 6. The values of the Young's modulus of the beam sections of the geocomposite (MPa) at sites 1 to 4 and 7-4 (a); connection of lateral shear of the geocomposite and the applied force when the length of the shoulder ballast equates $23 \mathrm{~m}(\mathrm{~b})$.

\subsection{Influence of penetration depth of polyurethane binding agent on mechanical behavior of railway track structure}

To determine the enfluence of the penetration depth of the polyurethane binding agent on the mechanical behavior of the railway track structure, the stress-strain state of the structure is calculated for different values of loads from the rolling stock applied in the form of a uniformly distributed static load as shown in Figure 2b. The value of the temporary vertical load from the rolling stock is taken into account with the prospects of development of railway vehicles in accordance with the Code of rules 35.13330.2011 "Bridges and pipes" equal to $137.34 \mathrm{kN} / \mathrm{m}$ per $1 \mathrm{~m}$ track. Considering the dynamic coefficient 1.357 (a Set of rules 35.13330.2011 "Bridges and pipes") the value of the temporary vertical load from the rolling stock used in the calculation of the stress-strain state of construction amounted to $186.37 \mathrm{kN} / \mathrm{m}$.

Figures 7 and 8 shows the dependency of the predicted vertical displacement on thickness of polyurethane-stabilized ballast layers at different loading conditions. It can be seen that the stabilization of ballast by polyurethane also allows to reduce the amount of vertical drawdown of the track up to $40 \%$.

(a)

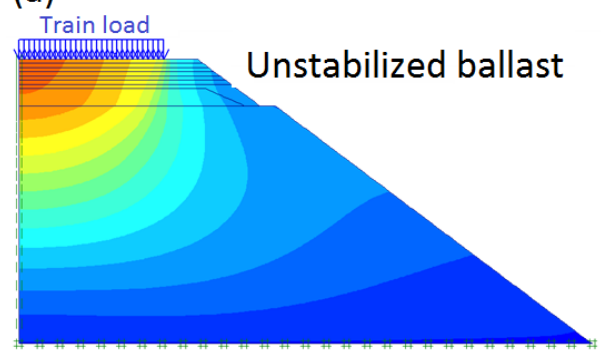

(b)

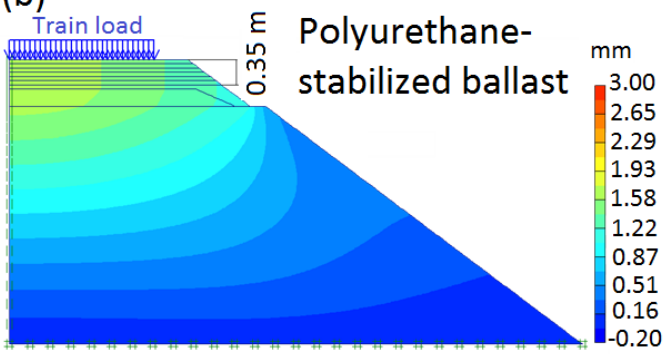

Fig. 7. Vertical displacement y-direction of ballast due to train loading $137.34 \mathrm{kH} / \mathrm{m}$. 


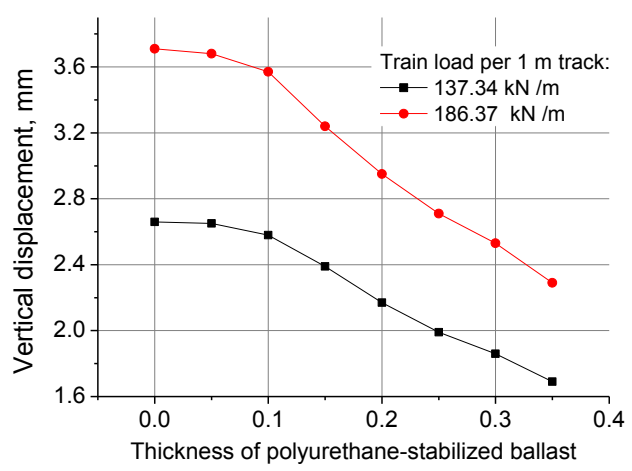

Fig. 8. FE prediction of vertical displacement of ballast at different loading conditions.

\section{Conclusions}

The analysis of the mechanical behavior of the shoulder of the ballast prism of the railway track reinforced with polyurethane binding agent is carried out by the method of finite element modeling. The values of the lateral displacement of the ballast shoulder are calculated depending on the model parameters, including the length of track section, the characteristics of the geocomposite, the value and time of application of the transverse force. It is found that the formation of geocomposite in the shoulder of the ballast prism results in a significant increase of resistance force of the rail-sleeper lattice to transverse travel, which is in conformity with the results of experimental measurements. As a result of the calculation of the stress-strain state of the structure and comparison of the results with the experiment shows the limitation of the model of linear elastic properties of geocomposite and the dependence of Young's modulus of geocomposite on deformation.

This work is supported by the Grant of the President of Russian Federation No. 14.W01.17.2210-MK of 22.02.2017.

\section{References}

1. B. Indraratna, S. Nimbalkar, C. Rujikiatkamjorn, Geotechnical Engineering 47(4), 50 (2016)

2. V. G. Albrecht, N. P. Vinogradov, N. B. Zverev et al, Continuous welded rail track (Transport, 2000)

3. P.K. Woodward, J. Kennedy, G.M. Medero, M. Banimahd, Proc. Inst. Mech. Eng. F. 226, 294 (2011)

4. L. Le Pen, W. Powrie, Proc. Inst. Mech. Eng. F. 225(2), 113 (2011)

5. M. Esmaeili, R. Nouri, K. Yousefian, Proc. Inst. Mech. Eng. F. 231(2), 175 (2017)

6. X. Perpinya, Reliability and Safety in Railway (Intech, 2012)

7. I. S. Baradei, A. A. Kareinen, V. V. Karpachevsky, Track and Track facilities 5, 31 (2010)

8. B. Indraratna, S.S. Nimbalkar, J.S. Vinod, Indian Geotechnical Conference (ICG 2013), 1 (2013)

9. S. Nimbalkar, B. Indraratna, Procedia Eng. 143, 1485 (2016) 
10. M.R. Hausmann, Engineering Principles of Ground Modification (McGraw-Hill Inc., 1990)

11. R.H. Karol, Chemical Grouting and Soil Stabilization (Marcel Dekker Inc., 2003)

12. O. Buzzi, S. Fityus, S.W. Sloan, Can. Geotech. J. 47(6), 623 (2010)

13. W. Ferdous, A. Manalo, G. Van Erp, T. Aravinthan, S. Kaewunruen, A. Remennikov, Compos. Struct. 134, 158 (2015)

14. A. Manalo, T. Aravinthan, W. Karunasena, A. Ticoalu, Compos. Struct. 92(3), 603 (2010)

15. A. Keene, J.M. Tinjum, T.B. Edil, Geotechnical Engineering Journal 45(1), 66 (2014)

16. J. Kennedy, P.K. Woodward, G. Medero, M. Banimahd, Constr. Build. Mater. 44, 615 (2013)

17. S. Pearson, R. Johnson, Using Polymers To Give Railway Ballast Designed Mechanical Properties (AusRAIL PLUS, (2011)

18. P.K. Woodward, J. Kennedy, G.M. Medero, M. Banimahd, Proc. Inst. Mech. Eng. F. 226(3), 257 (2012)

19. A.A. Kruglikov, V.A. Yavna, Y.M. Ermolov, A.G. Kochur, Z.B. Khakiev, Transportation Geotechnics 11, 133 (2017)

20. R.A. Van den Bosch, Rail Engineering International Edition 2, 7 (2007)

21. A. De Iorio, M. Grasso, F. Penta, G.P. Pucillo, V. Rosiello, Fracture and Structural Integrity 30, 578 (2014)

22. T. Sussmann, A. Kish, M. Trosino, Transp Res Rec. 1825(1), 56 (2003)

23. A.A. Kruglikov, G.I. Lazorenko, Y.M. Ermolov, V.A. Yavna, Geophysics 2015 - 11th EAGE International Scientific and Practical Conference and Exhibition on Engineering and Mining Geophysics 32DUMMY (2015) 